\title{
Eficácia Comunicacional na Docência Universitária - A Perspectiva de Estudantes e Professores
}

\author{
Arménio Rego ${ }^{1}$ \\ Universidade de Aveiro
}

\begin{abstract}
RESUMO - O artigo está animado por três objectivos inter-relacionados: a) confirmar a valia psicométrica do instrumento de medida da eficácia comunicacional dos professores do ensino superior proposto por Rego (2000); b) aferir o grau em que os comportamentos comunicacionais subjacentes ao instrumento são valorizados pelos professores e estudantes; c) explorar caminhos de melhoria da qualidade no ensino superior, especialmente no plano do processo ensino-aprendizagem. Foi recolhida uma amostra composta por 131 professores do ensino superior e 87 estudantes - ambos descreveram os comportamentos de um antigo professor à sua escolha e pontuaram a respectiva eficácia comunicacional. Os resultados sugerem o seguinte: a) é preferível trabalhar com 5 dimensões comunicacionais (comportamento de apoio, facilitação da comunicação, conscienciosidade pedagógica, cortesia e (não) leitura exclusiva de textos) em vez das 4 propostas por Rego; b) estas dimensões explicam cerca de $80 \%$ da variância nas cotações de eficácia comunicacional atribuídas pelos inquiridos aos seus antigos mestres; c) apesar de algumas diferenças, professores e estudantes denotam concepções convergentes acerca do significado da eficácia comunicacional docente.
\end{abstract}

Palavras-chave: comunicação docente universitária; qualidade no ensino superior; processo ensino-aprendizagem.

\section{Communication Effectiveness of University Teachers - The Students' and Teachers' Point of View}

\begin{abstract}
The paper aims at showing: a) the psychometric properties of the instrument for measuring communication effectiveness of university teachers proposed by Rego (2000); b) how teachers and students value the behaviors included in the instrument; c) how these behaviors can promote the quality in higher education. The sample comprises 131 university teachers and 87 students, who described the behaviors of a former teacher of their choice and evaluated their communication effectiveness. The main findings are as follow: a) the five-factor model (supporting behavior, communication facilitation; pedagogical conscientiousness; courtesy; "just reading of the texts") fits the data better than the four-factor model proposed by Rego; b) the five dimensions explain about $80 \%$ of the communication effectiveness score given by individuals to the teachers; c) in spite of some differences between students and teachers, they show convergent points of view about what "a good communicator teacher" means.
\end{abstract}

Key words: communication effectiveness of university teacher; quality in higher education; quality in teaching-learning process.

\begin{abstract}
A boa comunicação é tão estimulante como o café, e torna o sono igualmente difícil. (Lindbergh, citado em Crainer, 1999, p. 41)
\end{abstract}

Eu acabara de recolher, junto dos estudantes, mais alguns dados para a realização deste estudo. Após participar na investigação, um aluno abeirou-se de mim e indagou-me acerca dos objectivos que me norteavam. Expliquei-lhe que era meu propósito conhecer as concepções dos estudantes e dos professores acerca da eficácia comunicacional dos docentes do ensino superior. A informalidade da conversa conduziu-me a explicar-lhe os resultados de pesquisas anteriores. Designadamente, mencionei-lhe que alguns estudos prévios (Rego, 2000) haviam revelado que essas concepções eram convergentes. Em jeito desconfortável, retorquiu: "Mas isso só revela que, apesar de terem abandonado a condição de alunos há muito tempo, os professores mantêm-se agarrados a mentalidades desactualizadas".

1 Endereço: Universidade de Aveiro, 3810-193 Aveiro (Portugal). Email: arego@egi.ua.pt.
Eu supusera que a convergência da evidência empírica exposta por Rego (2000) era "atraente". Nas minhas cogitações, havia-se-me deparado um conjunto de comportamentos em torno dos quais os professores e alunos convergiam. No meu espírito, as "vantagens" para os estudantes eram óbvias. Designadamente, aos professores passava a ser mais difícil alegar que as concepções dos estudantes eram ingénuas e/ou enviesadas - a não ser que também assumissem o seu próprio espírito naif. Mas este aluno não projectava sobre os dados de Rego a lógica que eu julgava estar neles impregnada. A contradição era evidente para mim - mas o pensamento deste estudante enquadrava-se num contexto "ideológico" que impedia que entre nós houvesse ... comunicação transparente. Em boa verdade, mais humildemente, eu deveria agora dizer: o pensamento de cada um de nós estava moldado por contextos mentais distintos (Heyman, 1996). Era uma espécie de "diálogo de surdos"!

Não conheço a extensão desta estranha "forma de ver". Mas a experiência sugere-me que uma das fontes mais perniciosas para a comunicação docente provém de estereótipos que professores e estudantes projectam mutuamente uns 
sobre os outros. Neste artigo, será exposta alguma evidência empírica que poderá contribuir para diminuir este (quase) fosso entre as duas partes intervenientes no processo comunicacional docente. Se, de facto, os dois interlocutores partilham concepções comuns nesta matéria, então ambos têm razões para o optimismo e dispõem de um ponto de partida desde o qual podem desenhar caminhos de compreensão mais frutuosos.

\section{Comunicação e Qualidade no Ensino Superior}

O movimento iniciado há algumas décadas em torno da qualidade nas/das empresas (v.g., Hackman \& Wageman, 1995; Ruyter, Wetzels \& Bloemer, 1998; Shemwell, Yavas \& Bilgin, 1998; Zbaracki, 1998) foi-se tornando - umas vezes paulatinamente, outras mais velozmente - um tópico concitador de grande interesse prático e científico no seio de diversas áreas não empresariais. Assim sucedeu com a qualidade do ensino e das instituições escolares, incluindo as do ensino superior (v.g., Bailey \& Bennett, 1996; Ellington \& Ross, 1994; Feigenbaum, 1994; Hansen \& Jackson, 1996; Helms \& Key, 1994; Horine, Hailey \& Rubach, 1993; Horsburgh, 1999; Montano \& Utter, 1999; O'Hair \& Odell, 1995; Race, 1994; Sallis, 1993; Schargel, 1994; Scharples, Slusher \& Swain,1996; Sirvanci, 1996; Rowley, 1996; Weller, 1994).

Sucede que a qualidade implica melhorias, e estas - quaisquer que sejam os domínios de aplicação - só podem ser abraçadas após identificação das fontes e áreas de actuação mais pertinentes. Neste particular domínio, importa reconhecer que o processo ensino-aprendizagem tem sido referido por diversos estudiosos da qualidade como uma das áreas de intervenção com maior potencial (v.g., Bailey \& Bennett, 1996; Ellington \& Ross, 1994; Hansen \& Jackson, 1996; Horsburgh, 1999; Rowley, 1996; Schargel, 1994; Yorke, 1997). Este artigo insere-se nesse quadro de preocupações. Ele representa a tradução de uma ideia aduzida por Lee Iacocca (citado em Crainer, 1999: 41), ao enunciar que "a competitividade de um país não começa na fábrica ou no laboratório de engenharia, mas na sala de aula”. E procura dar resposta a um desafio eloquentemente declarado por Hansen \& Jackson (1996):

"Apesar do extenso discurso sobre a qualidade, a actividade nuclear das universidades - a docência - permanece em grande medida intacta. ... A menos que se actue sobre $o$ processo ensino-aprendizagem, as mudanças na gestão da qualidade suscitarão, apenas, benefícios diminutos" (pp. 211-212; sublinhado nosso).

Parece indubitável que este é um campo prenhe de dificuldades (v.g., Helms \& Key, 1994; Rowley, 1996). Mas as dificuldades nem sempre consubstanciam obstáculos intransponíveis. É frequente, aliás, que delas sobressaiam duas lógicas possíveis: uma barreira e ... uma oportunidade. Elas podem constituir, até, um convite à criatividade, investigação, reflexão e descoberta de linhas de orientação potencialmente contributivas de melhores desempenhos individuais e organizacionais.
Ademais, alguns caminhos proveitosos têm vindo a ser rasgados. Na verdade, é identificável na literatura um atraente catálogo de comportamentos docentes com potenciais efeitos positivos sobre os estudantes e, globalmente, o processo ensino-aprendizagem (v.g., Ellington \& Ross, 1994; Helms \& Key, 1996; Horsburgh, 1999; Marsh, Hau, Chung \& Siu, 1998; Rowley, 1996; Stringer \& Irving, 1998). Se procedermos a uma leitura cuidadosa destes comportamentos, verificaremos que são numerosos os que denotam cariz comunicacional. Citam-se ilustrativamente o feedback da aprendizagem pontual e justo, entusiasmo e dinamismo, espírito de diálogo e práticas reflexivas partilhadas, actuação amistosa do docente, humor na apresentação das matérias, encorajamento da discussão, aulas estimulantes e desafiantes, preparação dos materiais de leccionação, clareza das explicações.

Este artigo situa-se, precisamente, neste domínio. O leitmotiv que o orquestra decorre da ideia de que "quase todos os problemas, conflitos, erros e incompreensões têm a sua génese, ao nível mais básico/profundo, num problema de comunicação (Alessandra \& Hunsaker, 1993, p. 11). Está animado pelo desejo de apresentar evidência empírica adicional tendo em vista três objectivos inter-relacionados: a) a validação do construto da eficácia comunicacional dos docentes do ensino superior proposto por Rego (2000); b) a confirmação da valia de alguns comportamentos comunicacionais para a qualidade do ensino superior; c) a exposição de actos que os docentes podem adoptar tendo em vista serem ... melhores professsores.

\section{O contruto da eficácia comunicacional dos docentes do ensino superior}

Quando se almeja contribuir para o progresso em uma determinada área científica, é fundamental dispor de instrumentos de medição psicometricamente válidos. Só desse modo se pode garantir que a extracção de ilações práticas (e susceptíveis de permitirem intervenções eficazes no "terreno”) não é enviesada por deficiências científicas metodológicas. Com a mira nessas finalidades, e baseando-se em estudo exploratório anterior (Rego \& Sousa, 2000), Rego (2000) propôs uma ferramenta cujos trabalhos de validação mediante análise factorial das componentes principais sugeriram quatro dimensões:

a) O comportamento empático incorpora actos comunicacionais de proximidade, participação e empenho, simplicidade e atractividade da linguagem, e apoio sócioafectivo.

b) A conscienciosidade pedagógica integra comportamentos atinentes à preparação da aula, sua estruturação e organização, e competência "técnica".

c) A (des)cortesia" respeita à (in)delicadeza e grau de (des) respeito no tratamento dos estudantes.

d) A quarta dimensão respeita à leccionação com base na leitura exclusiva de textos.

Esses trabalhos abarcaram uma amostra constituída por 132 estudantes universitários e 69 professores do mesmo nível de ensino. O investigador convidou estes professores a 


\section{Eficácia Comunicacional na Docência Universitária}

descreverem os comportamentos comunicacionais de antigos docentes, e a atribuirem-lhes uma cotação global de eficácia comunicacional. A estratégia de abordagem dos estudantes foi similar, apenas divergindo no facto de terem sido instruídos para reflectirem sobre os seus actuais professores. Os resultados podem ser estruturados em torno de duas linhas marcantes:

a) Estas quatro dimensões explicam cerca de $80 \%$ da variância da cotação global de eficácia comunicacional atribuída pelos inquiridos aos professores sobre os quais se exprimiram.

b) Os estudantes valorizam mais o comportamento empático que os professores, o inverso ocorrendo com a conscienciosidade pedagógica. Mas é notória a convergência entre ambos a propósito do significado da docência comunicacionalmente eficaz.

Estes trabalhos denotam elementos de inquestionável mérito. Primeiro: as consistências internas de todas as dimensões situam-se entre 0,85 e 0,92 , assim ultrapassando largamente o mínimo de 0,70 sugerido por Nunnally (1978). Segundo: o instrumento foi testado com uma amostra constituída por estudantes e professores. Terceiro: as quatro dimensões (com especial destaque para o comportamento empático e a conscienciosidade pedagógica) denotam elevado poder preditivo da notação global de eficácia comunicacional. No entanto, o estudo padece de algumas limitações:

a) Os inquiridos foram recolhidos numa só instituição universitária.

b) Não foram considerados inquiridos oriundos de instituições politécnicas.

c) A variável dependente (cotação global de eficácia comunicacional) foi medida através de um só item.

d) As variáveis indepentendes (comportamentos comunicacionais) e a dependente foram recolhidas na mesma fonte, o que pode gerar riscos de variância do método comum (Podsakoff \& Organ, 1986).

e) Não foi consignada a possibilidade de a (in)eficácia comunicacional ser contingente de aspectos como a área disciplinar ou a natureza (teórica, prática...) da disciplina leccionada.

f) A última dimensão comunicacional atrás mencionada foi medida através de, apenas, dois itens. Esta situação não é desejável quando se pretende efectuar análises factoriais confirmatórias (Byrne, 1998; Joreskog \& Sorbom, 1993), pois são desejáveis, pelo menos, três descritores.

g) A primeira dimensão é medida por itens cujo conteúdo é, pelo menos aparentemente, algo fluido. Esta situação pode advir das particularidades atinentes à técnica da análise factorial das componentes principais (Kline, 1994), que tende a congregar no primeiro factor a maior parte das variáveis.

Para tentar superar algumas destas limitações, e para fornecer evidência empírica adicional da dimensionalização anteriormente obtida, a presente investigação recolheu dados em diversas instituições de ensino superior, considerou a área disciplinar leccionada pelo docente sobre o qual os inquiridos se debruçaram, enriqueceu a última dimensão factorial com um descritor adicional, recorreu a uma medida multi-item de desempenho comunicacional, e testou vários modelos dimensionais através da técnica da análise factorial confirmatória.

\section{Metodologia}

A amostra é composta por 218 indivíduos. 131 exerciam funções docentes em duas universidades e duas instituições politécnicas portuguesas. Distribuíam-se por todas as categorias da carreira docente. Os restantes 87 eram estudantes na Universidade de Aveiro, e frequentavam cursos nas áreas da educação, gestão, economia e engenharia industrial. Os alunos foram abordados directa e pessoalmente, tendo a resposta sido devolvida presencialmente ao investigador. Os professores foram contactados através de missiva colocada na sua caixa/cacifo de correspondência. A cada docente foi fornecido um sobrescrito de resposta sem franquia, para devolução. Dado que este processo envolveu 400 docentes, a taxa de devolução foi de $32 \%$. Foi usada a mesma estratégia com todos os inquiridos:

a) Foi-lhes solicitado que pensassem num antigo docente à sua escolha.

b) Foi-lhes enfatizado que a escolha poderia recaír sobre qualquer docente, independentemente do sexo, idade e área disciplinar, de gostarem ou não dele, e de o considerarem ou não competente. A única condição proposta foi que conhecessem bem a forma como o docente em causa se comportava em sala de aula.

c) Apresentou-se-lhes um questionário contendo os 23 itens remanescentes da análise factorial obtida por Rego (2000), aos quais foi acrescentado um descritor destinado a medir a última dimensão comunicacional atrás citada.

d) Convidámo-los a assinalarem em que grau essas afirmações se aplicavam ao docente sobre o qual reflectiam, numa escala de 1 ("não se aplica rigorosamente nada") a 7 ("aplica-se completamente").

e) Foram depois foram instruídos para assinalarem, através de seis escalas de diferencial semântico (ver anexo), o grau de eficácia comunicacional do docente avaliado.

f) Finalmente, foram convidados a atribuir ao docente escolhido uma cotação global de eficácia comunicacional, numa escala de 0 ("péssimo comunicador") a 20 ("excelente comunicador"). Esta escala tem a vantagem de ser igual à usada pelos docentes na avaliação dos estudantes, permitindo avaliar em que medida os inquiridos consideram que os docentes escolhidos são ou não "aprovados" (nota igual ou superior a 9,5) no "teste" da eficácia comunicacional.

\section{Resultados}

A análise factorial das componentes principais aplicada às seis variáveis de eficácia revelou-se pertinente (KMO: 0,91; teste de esfericidade de Bartlett: 1770,93, $p=0,0000$ ). A consideração das componentes principais com valor pró- 
Tabela 1. Análise factorial das componentes principais aplicada aos dados de eficácia docente (ver anexo).

\begin{tabular}{lc}
\hline Itens (ver anexo) & Saturações \\
\hline Excelência da comunicação & 0,92 \\
Exemplo a seguir & 0,94 \\
Prazer de assistir às aulas & 0,96 \\
Excelência docente & 0,94 \\
Pertinência de ir às aulas & 0,93 \\
Impacto das aulas sobre a aprendizagem & 0,83 \\
Variância explicada & $87,6 \%$ \\
Alpha de Cronbach & 0,97 \\
\hline
\end{tabular}

prio superior a 1 sugeriu a extracção de um só factor, explicando $87,6 \%$ da variância total (tabela 1). A consistência interna cifra-se em 0.97 .

Os dados atinentes aos comportamentos comunicacionais foram submetidos a uma análise factorial confirmatória (Byrne, 1998; Joreskog \& Sorbom, 1993), à luz do modelo tetra-factorial emergente em Rego (2000). Os índices de ajustamento não se revelaram satisfatórios, o que não é surpreendente se atendermos à elevada quantidade de itens. Procedêmos, então, à remoção de descritores de acordo com os valores dos índices de modificação e dos resíduos standardizados. O modelo resultante está exposto na tabela 2, denotando índices de ajustamento bastante satisfatórios. Os coeficientes de consistência interna são superiores a 0,70 (Nunnally, 1978). Foram posteriormente testados dois modelos alternativos:

a) Num deles, todos os itens foram imputados a um único factor. Os índices de ajustamento revelaram-se insatisfatórios (v.g., RMSEA: 0,163; GFI: 0,68).

b) No outro, atendendo ao conteúdo semântico dos descritores da dimensão "comportamento empático", procedeuse à sua separação em dois factores. O primeiro contém três itens, representando o grau em que o professor adopta uma postura comunicacional de natureza apoiante. $\mathrm{O}$ outro integra 4 descritores cujo conteúdo semântico trans-

Tabela 2. Análise factorial confirmatória (solução completamente standardizada)

\begin{tabular}{|c|c|c|c|c|}
\hline & \multicolumn{2}{|c|}{ Dados da actual pesquisa } & \multicolumn{2}{|c|}{ Dados de Rego (2000) } \\
\hline & 4 factores & 5 factores & 4 factores & 5 factores \\
\hline Comportamento empático & $(0,87)$ & & $(0,90)$ & \\
\hline Comportamento apoiante & & $(0,84)$ & & $(0,87)$ \\
\hline Facilitava a participação dos alunos no processo de comunicação. & 0,76 & 0,78 & 0,80 & 0,80 \\
\hline Empenhava-se activamente para que os al unos compreendessem o que ele estava dizendo. & 0,75 & 0,75 & 0,91 & 0,92 \\
\hline A poiava os alunos no seu processo de aprendizagem em sala de aula. & 0,65 & 0,88 & 0,73 & 0,72 \\
\hline Facilitação da comunicação & & $(0,76)$ & & $(0,80)$ \\
\hline Sabia fazer humor quando era necessário. & 0,64 & 0,69 & 0,72 & 0,75 \\
\hline Sabia complementar a exposição oral com linguagem não-verbal (ex: gestual ou corporal). & 0,54 & 0,67 & 0,72 & 0,77 \\
\hline Utilizava uma linguagem simples. & 0,75 & 0,55 & 0,65 & 0,66 \\
\hline Complementava a exposição da matéria com exemplos práticos. & 0,84 & 0,78 & 0,66 & 0,69 \\
\hline Conscienciosidade pedagógica & $(0,86)$ & $(0,86)$ & $(0,84)$ & $(0,84)$ \\
\hline A exposição das matérias era muito confusa (I). & 0,72 & 0,72 & 0,83 & 0,84 \\
\hline $\begin{array}{l}\text { Quando comunicava connosco, percebia-se que sabia do que estava a falar } \\
\text { (isto é, que tinha bons conhecimentos da matéria). }\end{array}$ & 0,68 & 0,68 & 0,65 & 0,65 \\
\hline A través do modo como falava, percebia-se que preparava bem as aulas. & 0,85 & 0,85 & 0,68 & 0,68 \\
\hline As aulas não tinham sequência lógica (I). & 0,70 & 0,70 & 0,69 & 0,68 \\
\hline Expunha a matéria de modo desorganizado (I). & 0,85 & 0,85 & 0,71 & 0,71 \\
\hline (Des)cortesia & $(0,79)$ & $(0,79)$ & $(0,84)$ & $(0,84)$ \\
\hline Era agressivo no modo como comunicava com os al unos (I). & 0,73 & 0,73 & 0,85 & 0,85 \\
\hline Tratava os al unos como "crianças" (I). & 0,69 & 0,69 & 0,71 & 0,71 \\
\hline Era indelicado no relacionamento com os alunos (I). & 0,83 & 0,83 & 0,84 & 0,84 \\
\hline (Não) leitura exclusiva de textos & $(0,90)$ & $(0,90)$ & $(0,89)$ & $(0,89)$ \\
\hline $\begin{array}{l}\text { Expunha a matéria, exclusivamente, lendo ou ditando (por ex: o livro, os transparentes, ou al gum } \\
\text { texto que trazia consigo) (I). }\end{array}$ & 0,90 & 0,90 & 0,84 & 0,83 \\
\hline Normalmente, apenas lia ou ditava os textos/livros que trazia escritos (I). & 0,92 & 0,92 & 0,95 & 0,97 \\
\hline Os alunos tinham que passar uma grande parte do tempo da aula a ouvir o que ele lia ou ditava (I). & 0,81 & 0,81 & * & $*$ \\
\hline \multicolumn{5}{|l|}{ Índices de aj ustamento } \\
\hline Qui-quadrado/Graus de liberdade & 1,9 & 1,7 & 2,4 & 2,3 \\
\hline Root mean square error of approximation & 0,064 & 0,058 & 0,085 & 0,084 \\
\hline Goodness of fit index & 0,89 & 0,90 & 0,86 & 0,87 \\
\hline Adjusted goodness of fit index & 0,85 & 0,86 & 0,81 & 0,81 \\
\hline Comparative fit index & 0,94 & 0,96 & 0,92 & 0,93 \\
\hline Incremental fit index & 0,94 & 0,96 & 0,92 & 0,93 \\
\hline Relative fit index & 0,87 & 0,88 & 0,85 & 0,85 \\
\hline
\end{tabular}

(I) A pontuação nestes itens foi invertida.

* Este item não foi considerado no estudo.

Os valores entre parêntesis representam os Alphas de Cronbach. 
parece um espírito facilitador da comunicação. Este modelo denota índices de ajustamento ligeiramente mais satisfatórios do que o modelo tetra-dimensional (tabela 2).

Esta evidência quase se replica na plenitude quando os dados de Rego (2000) são submetidos a idêntica operação confirmatória. Em qualquer caso, convém registar que os índices de ajustamento são menos satisfatórios do que os referentes à amostra do presente estudo. As consistências internas cifram-se, no entanto, em valores consideravalmente elevados.

A tabela 3 expõe as médias, desvio-padrão e correlações entre as variáveis em estudo. Para efeitos comparativos, são apresentados igualmente os resultados dos dados de Rego (2000), exceptuando os referentes ao índice compósito de eficácia comunicacional (que não fora medido). Em geral, os dados sugerem que as cinco dimensões comportamentais se correlacionam bastante acentuadamente entre si e, de modo especial, com os indicadores de eficácia comunicacional. Esta evidência é convergente para as amostras do presente estudo e da pesquisa de Rego (2000).

Na tabela 4 estão consignados os resultados das análises de regressão para as duas variáveis dependentes: a cotação global de eficácia comunicacional e o indicador compósito. Para efeitos comparativos, expõem-se os resultados atinentes ao estudo de Rego (2000). As variâncias explicadas ciframse em torno de $80 \%$, parecendo ser recomendável o recurso ao indicador compósito (para o qual o poder preditivo das variáveis comunicacionais é superior). Consistentemente, a variável cortesia perde poder explicativo quando conjugada com as restantes dimensões comportamentais.

A tabela 5 apresenta os resultados das análises de regressão para os dois indicadores (o simples e o compósito) da eficácia comunicacional docente, estabelecendo a comparação para professores e estudantes. Duas tendências ressaltam claramente: a) as variáveis comportamentais explicam mais vincadamente o indicador compósito do que o simples; b) relativamente aos estudantes, os professores concedem mais valor à conscienciosidade, o inverso ocorrendo com o comportamento de apoio.

A tabela 6 patenteia novas regressões tendo em vista a comparação entre as disciplinas de duas áreas: humanísticas (línguas, literatura, história, filosofia, psicologia...) e ciências (física, química, engenharias, biologia, geologia....). Os dados reiteram que as variáveis comunicacionais denotam maior poder preditivo do indicador de eficácia compósito do que do indicador simples. Renovam o poder explicativo negligenciável da cortesia. Ademais, não revelam diferenças notórias entre as duas áreas disciplinares. Nesta matéria,

Tabela 3. Médias, desvio-padrão e correlações.

\begin{tabular}{|c|c|c|c|c|c|c|c|c|}
\hline & Média & DP & 1 & 2 & 3 & 4 & 5 & 6 \\
\hline \multirow[t]{2}{*}{ 1. Comportamento de apoio } & 4,7 & 1,5 & - & & & & & \\
\hline & 4,5 & 1,5 & & & & & & \\
\hline \multirow[t]{2}{*}{ 2. Facilitação da comunicação } & 4,7 & 1,3 & 0,71 & - & & & & \\
\hline & 4,5 & 1,4 & 0,79 & & & & & \\
\hline \multirow[t]{2}{*}{ 3. Conscienciosidade pedagógica } & 5,7 & 1,1 & 0,52 & 0,57 & - & & & \\
\hline & 5,2 & 1,3 & 0,56 & 0,56 & & & & \\
\hline \multirow[t]{2}{*}{ 4. Cortesia } & 6,1 & 1,0 & 0,57 & 0,50 & 0,51 & - & & \\
\hline & 5,6 & 1,4 & 0,56 & 0,52 & 0,41 & & & \\
\hline \multirow[t]{2}{*}{ 5. (Não) leitura exclusiva de textos } & 5,6 & 1,6 & 0,51 & 0,58 & 0,55 & 0,46 & - & \\
\hline & 5,3 & 1,9 & 0,54 & 0,47 & 0,50 & 0,42 & & \\
\hline 6. Eficácia compósita & 5,4 & 1,6 & 0,74 & 0,76 & 0,80 & 0,57 & 0,72 & - \\
\hline \multirow[t]{2}{*}{ 7. Cotação global de eficácia comunicacional } & 14,9 & 4,6 & 0,73 & 0,76 & 0,75 & 0,55 & 0,69 & 0,95 \\
\hline & 13,5 & 4,9 & 0,80 & 0,82 & 0,73 & 0,55 & 0,61 & \\
\hline
\end{tabular}

Todos os coeficientes são estatisticamente significativos para $p<0,001$.

Os valores da segunda linha referem-se aos dados de Rego (2000). Essa cifra não surge para a eficácia compósita porque essa variável não foi medida.

Tabela 4. Análises de regressão para a eficácia comunicacional docente.

\begin{tabular}{|c|c|c|c|}
\hline & \multicolumn{2}{|c|}{ Dados da actual pesquisa } & \multirow{2}{*}{$\begin{array}{c}\text { Dados de Rego (2000) } \\
\text { Eficácia global }\end{array}$} \\
\hline & Indicador compósito de eficácia & Eficácia global & \\
\hline Comportamento de apoio & $0,25 * * *$ & $0,25 * * *$ & $0,22 * * *$ \\
\hline Facilitação da comunicação & $0,21 * * *$ & $0,25 * * *$ & $0,40 * * *$ \\
\hline Conscienciosidade pedagógica & $0,41^{* * *}$ & $0,36 * * *$ & $0,30 * * *$ \\
\hline Cortesia & 0,02 & $-0,01$ & 0,03 \\
\hline (Não) leitura exclusiva de textos & $0,24 * * *$ & $0,22 * * *$ & $0,14 * * *$ \\
\hline $\mathrm{F}$ & $232,44 * * *$ & $160,66 * * *$ & $180,43 * * *$ \\
\hline $\mathrm{R}^{2}$ & $85 \%$ & $79 \%$ & $83 \%$ \\
\hline $\mathrm{R}^{2}$ ajustado & $84 \%$ & $79 \%$ & $82 \%$ \\
\hline
\end{tabular}

$* * * p<0,001$ 


\section{A. Rego}

Tabela 5. Regressões para a eficácia comunicacional (comparação entre as sub-amostras de professores e estudantes).

\begin{tabular}{|c|c|c|c|c|}
\hline & \multicolumn{2}{|c|}{ Indicador compósito de eficácia } & \multicolumn{2}{|c|}{ Cotação de eficácia global } \\
\hline & $\begin{array}{l}\text { Professores } \\
(\mathbf{n}=131)\end{array}$ & $\begin{array}{l}\text { Alunos } \\
(n=87)\end{array}$ & $\begin{array}{c}\text { Professores } \\
(\mathbf{n}=131)\end{array}$ & $\begin{array}{l}\text { Alunos } \\
(n=87)\end{array}$ \\
\hline Comportamento de apoio & $0,20 * * *$ & $0,30 * * *$ & $0,17 * *$ & $0,43 * * *$ \\
\hline Facilitação da comunicação & $0,17 * * *$ & $0,29 * *$ & $0,27 * * *$ & $0,20 *$ \\
\hline Conscienciosidade pedagógica & $0,43 * * *$ & $0,38 * * *$ & $0,40 * * *$ & $0,30 * * *$ \\
\hline Cortesia & 0,06 & $-0,06$ & 0,03 & $-0,05$ \\
\hline (Não) leitura exclusiva de textos & $0,30 * * *$ & $0,13^{*}$ & $0,23 * * *$ & $0,15^{*}$ \\
\hline $\mathrm{F}$ & $149,19 * * *$ & $92,40 * * *$ & $88,51 * * *$ & $72,23 * * *$ \\
\hline $\mathrm{R}^{2}$ & $86 \%$ & $85 \%$ & $78 \%$ & $82 \%$ \\
\hline $\mathrm{R}^{2}$ aj ustado & $85 \%$ & $84 \%$ & $77 \%$ & $81 \%$ \\
\hline
\end{tabular}

$* p<0,05 \quad * * p<0,01 \quad * * * p<0,001$

Tabela 6. Regressões para a eficácia comunicacional (comparação entre duas áreas disciplinares).

\begin{tabular}{|c|c|c|c|c|}
\hline & \multicolumn{2}{|c|}{ Indicador compósito de eficácia } & \multicolumn{2}{|c|}{ Cotação de eficácia global } \\
\hline & $\begin{array}{l}\text { Humanísticas } \\
(\mathbf{n}=93)\end{array}$ & $\begin{array}{l}\text { Ciências } \\
(n=82)\end{array}$ & $\begin{array}{l}\text { H umanísticas } \\
\qquad(\mathbf{n}=93)\end{array}$ & $\begin{array}{l}\text { Ciências } \\
(n=82)\end{array}$ \\
\hline Comportamento de apoio & $0,29 * * *$ & $0,24 * * *$ & $0,34 * * *$ & $0,30 * * *$ \\
\hline Facilitação da comunicação & $0,14^{*}$ & $0,24 * * *$ & 0,13 & $0,27 * * *$ \\
\hline Conscienciosidade pedagógica & $0,37 * * *$ & $0,41^{* * *}$ & $0,43 * * *$ & $0,34 * * *$ \\
\hline Cortesia & 0,05 & $-0,03$ & 0,00 & $-0,07$ \\
\hline (Não) leitura exclusiva de textos & $0,30 * * *$ & $0,27 * * *$ & $0,22 * * *$ & $0,24 * * *$ \\
\hline $\mathrm{F}$ & $133,45^{* * *}$ & $105,02 * * *$ & $107,49 * * *$ & $65,47^{* * *}$ \\
\hline$R^{2}$ & $89 \%$ & $88 \%$ & $86 \%$ & $81 \%$ \\
\hline $\mathrm{R}^{2}$ ajustado & $88 \%$ & $87 \%$ & $86 \%$ & $80 \%$ \\
\hline
\end{tabular}

$* p<0,05 \quad * * p<0,01 \quad * * * p<0,001$

Tabela 7. Configurações comunicacionais docentes.

\begin{tabular}{|c|c|c|c|c|c|c|c|}
\hline & $\begin{array}{c}\text { G rupo } 1 \\
\text { A penas } \\
\text { simpáticos } \\
(\mathbf{n}=17)\end{array}$ & $\begin{array}{c}\text { Grupo } 2 \\
\text { Fracos } \\
\text { comunicadores } \\
\text { (n= 18) }\end{array}$ & $\begin{array}{l}\text { Grupo } 3 \\
\text { Regulares } \\
(\mathbf{n}=19)\end{array}$ & $\begin{array}{c}\text { G rupo } 4 \\
\text { Conscienciosos } \\
\text { e corteses } \\
(\mathbf{n}=\mathbf{2 9})\end{array}$ & $\begin{array}{c}\text { Grupo } 5 \\
\text { Bons } \\
\text { comunicadores } \\
(n=80)\end{array}$ & $\begin{array}{c}\text { Grupo } 6 \\
\text { Excelentes } \\
\text { comunicadores } \\
(\mathbf{n}=\mathbf{5 5 )}\end{array}$ & $\begin{array}{l}\text { Q uantidade de } \\
\text { pares de grupos } \\
\text { diferentes* }\end{array}$ \\
\hline \multicolumn{8}{|c|}{ Comportamentos comunicacionais (escala 1-7) } \\
\hline Comportamento de apoio & 2,9 & 2,2 & 4,6 & 3,4 & 5,1 & 6,2 & 12 \\
\hline Facilitação da comunicação & 2,9 & 2,7 & 4,4 & 4,2 & 5,0 & 6,0 & 12 \\
\hline Conscienciosidade pedagógica & 4,1 & 4,0 & 5,0 & 5,5 & 6,2 & 6,4 & 12 \\
\hline Cortesia & 5,5 & 4,5 & 5,5 & 5,6 & 6,5 & 6,6 & 11 \\
\hline (Não) leitura exclusiva de textos & 1,6 & 4,3 & 4,0 & 6,1 & 6,2 & 6,9 & 13 \\
\hline M édia das 5 dimensões** & 3,4 & 3,5 & 4,7 & 5,0 & 5,8 & 6,4 & 13 \\
\hline \multicolumn{8}{|c|}{ Indicador simples de eficácia comunicacional (escala 1-20) } \\
\hline A tribuída pelos docentes & 7,9 & 7,0 & 10,0 & 15,2 & 17,1 & 18,3 & 10 \\
\hline A tribuída pelos estudantes & 6,0 & 6,1 & 11,0 & 11,3 & 16,4 & 18,5 & 11 \\
\hline \multicolumn{8}{|c|}{ Indicador compósito de eficácia comunicacional (escala 1-7) } \\
\hline A tribuída pelos docentes & 2,6 & 2,6 & 4,0 & 5,3 & 6,1 & 6,6 & 13 \\
\hline A tribuída pelos estudantes & 2,1 & 2,5 & 4,8 & 4,4 & 5,9 & 6,7 & 12 \\
\hline Área disciplinar de ciências & 2,4 & 2,3 & 4,6 & 4,9 & 6,1 & 6,5 & 12 \\
\hline Área disciplinar de humanidades & 2,2 & 2,4 & 4,7 & 5,1 & 6,1 & 6,8 & 13 \\
\hline
\end{tabular}

* Teste Scheffé $(p<0,05)$

** Alpha de Cronbach: 0,85

o único dado enfatizável parece ser o que sugere que a facilitação da comunicação é mais ponderado pelos inquiridos que escolheram docentes de disciplinas da área das ciências.

A tabela 7 expõe as configurações comunicacionais dos docentes escolhidos pelos inquiridos, assim como as respectivas cotações simples e compósita de eficácia comunica- cional. A sua edificação foi encetada com uma análise de clusters (método: ward; distância: euclidiana ao quadrado) baseada nos dados atinentes aos comportamentos comunicacionais. Depois, através de uma análise de variância, compararam-se os valores médios de cada agrupamento, quer no que concerne aos comportamentos, quer no que respeita 
aos dois indicadores de eficácia comunicacional. Para estas duas últimas variáveis, foram calculadas as cotações referentes a cada tipo de inquiridos e áreas disciplinares. As designações e caracterização dos grupos são as seguintes:

a) O grupo 1 integra docentes que foram denominados "Apenas simpáticos". Expressam fracas cotações nas diversas dimensões comunicacionais, excepto na cortesia. Assemelham-se a docentes "simpáticos" mas sem qualidades comunicacionais pertinentes. Tanto os estudantes como os professores inquiridos os consideram muito fracos comunicadores.

b) No grupo 2 inserem-se docentes com perfil de "Fracos comunicadores". Denotam cotações pobres em todas as categorias comunicacionais, especialmente no que concerne ao comportamento apoiante e à facilitação da comunicação. Ambos os tipos de inquiridos lhes atribuem fracas cotações de eficácia comunicacional.

c) O grupo 3 representa docentes que podem ser apelidados de "Regulares" por denotarem cotações intermédias em todas as dimensões comunicacionais. As pontuações de eficácia que receberam dos inquiridos situam-se igualmente na linha intermédia.

d) Os docentes do grupo 4 foram designados "Conscienciosos e corteses". São corteses, preparam e organizam as aulas, não ministram as lições com base na leitura exclusiva de textos - mas são pouco propensos a comportamentos comunicacionais apoiantes e facilitadores. Os professores inquiridos consideram-nos bons comunicadores, mas essa concepção não é partilhada pelos estudantes. De acordo, aliás, com a evidência manifestada pelas análises de regressão, é provável que os alunos, relativamente aos professores, sejam mais sensíveis às duas primeiras categorias comunicacionais - o inverso ocorrendo com a conscienciosidade.

e) No grupo 5 estão inseridos docentes com perfil de "Bons comunicadores". Denotam elevadas cotações em todas as dimensões comunicacionais, e são considerados bastante eficazes comunicacionalmente por ambos os tipos de inquiridos.

f) Finalmente, o grupo 6 abarca docentes muito bem cotados em todas as categorias comunicacionais. Foram designados "Excelentes comunicadores", fazendo jus ao facto de ambos os tipos de inquiridos lhes concederem pontuações de eficácia comunicacional situadas nos extremos das escalas.

Enfatize-se que as pontuações referentes às duas áreas disciplinares denotam diferenças que podem ser consideradas desprezíveis. Este facto reforça a ideia apontada pela regressões expostas na tabela 6: em geral, a valorização das dimensões comportamentais não é contingente do tipo de disciplina considerada pelos inquiridos.

\section{Análise, Discussão e Conclusões}

O primeiro elemento digno de meritória citação é o que concerne à valia psicométrica do instrumento aqui proposto. Vários aspectos são sintomáticos: a) o modelo penta- factorial ajusta-se satisfatoriamente aos dados; b) esse ajustamento é extensivo aos dados de Rego (2000), embora em grau menos enfático; c) os lambdas são elevados, nunca descem a barreira de 0.50 , e expressam valores que tendem a ultrapassar o nível de 0.70 ; d) as consistências internas cumprem invariavelmente o requisito mínimo de 0.70 , e quase sempre ultrapassam a cifra de 0.80 . Acrescente-se que a última dimensão, medida por apenas dois descritores na pesquisa de Rego (2000), é agora traduzida por três itens, o mínimo recomendável (Byrne, 1998).

Em segundo lugar, parece haver vantagens em discernir duas dimensões na categoria empática que Rego (2000) havia detectado. Com efeito, essa partição permite incrementos, embora ligeiros, nos índices de ajustamento do modelo factorial confirmatório. Esse progresso não justifica, per se, a adopção definitiva do esquema penta-factorial. Todavia, se adicionarmos a esse facto a evidência reveladora de que as duas dimensões autónomas expressam poderes preditivos significativos da eficácia comunicacional, a opção apresenta-se com maior verosimilhança teórico-empírica. Acresce que as duas variáveis não expressam capacidades preditivas paralelas, o que reitera a pertinência de as discernir. Ou seja: se se pretende melhorar o conhecimento dos factores contributivos da eficácia comunicacional docente (seja para efeitos de investigação ou de intervenção no "terreno"), a divisão pode ser enriquecedora.

Em terceiro lugar, é reiterado o elevado poder explicativo das dimensões comportamentais para as cotações de eficácia comunicacional. A ordem de grandeza das variâncias explicadas situa-se no mesmo patamar das expressas em Rego (2000), mas a presente pesquisa patenteia uma vantagem relativa de considerável relevância: o recurso a um indicador de eficácia compósito possibilita a obtenção de poderes preditivos superiores aos extraídos para um indicador simples.

Quarto: este indicador compósito denota uma consistência interna de notória dimensão (0.97), o que representa uma mais-valia considerável do ponto de vista da sua validade e do seu contributo para a validação do instrumento expresso neste artigo.

Quinto: os dados de Rego (2000) foram extraídos de uma só instituição universitária. Distintamente, o actual estudo englobou docentes de duas instituições universitárias e duas politécnicas. Este alargamento contribui para robustecer a evidência empírica que vai sendo produzida neste domínio ainda incipiente.

Sexto: Rego (2000) não considerou a possibilidade de a relevância atribuída aos comportamentos comunicacionais pelos inquiridos ser contingente do tipo de disciplina leccionada pelo professor escolhido para análise. Ao contrário, a presente pesquisa ponderou-a, contribuindo também para robustecer a relevância teórica, empírica e prática das categorias comunicacionais estudadas.

Sétimo: o facto de se obterem as variáveis independentes (comportamentos comunicacionais) e dependentes (eficácia) na mesma fonte pode induzir efeitos de variância do método comum (Podsakoff \& Organ, 1986). Ou seja: em 
certa medida, os comportamentos comunicacionais podem explicar fortemente as cotações de eficácia pelo facto de ambas as variáveis serem notadas pelas mesmas pessoas. Os inquiridos podem adoptar um raciocínio do género: "este docente adopta estes comportamentos em elevado grau, logo é comunicacionalmente eficaz". Daqui deriva a necessidade de pesquisas vindouras adoptarem metodologias longitudinais, experimentais ou, mesmo, de dupla fonte (v.g., alguns inquiridos descrevem os comportamentos de um docente, e outros inquiridos classificam-no do ponto de vista da eficácia comunicacional).

Transponhamos, agora, a análise para a compreensão do significado prático dos dados expostos. Neste plano, importa acentuar os seguintes registos:

a) Tal como Rego (2000) já havia diagnosticado, a cortesia perde poder preditivo da eficácia comunicacional quando é ponderada conjuntamente com as restantes variáveis. Daqui não decorre, necessariamente a sua irrelevância. Pode aliás suceder que haja interacção entre as cinco categorias comportamentais. Por exemplo, um docente descortês pode "perder" qualidades comunicacionais junto dos destinatários das suas lições - mesmo que bem pontuado nos restantes aspectos.

b) Este é um caminho que pesquisas futuras poderão explorar mais proficuamente. De qualquer modo, importa realçar que, na presente pesquisa, o poder preditivo das restantes quatro dimensões para o indicador compósito de eficácia é maior para os docentes menos corteses (84\% de variância explicada) do que para os mais corteses (70\%). A tradução prática deste dado é simples: os professores são considerados especialmente fracos comunicadores quando uma baixa cotação numa dimensão comportamental se conjuga com baixo nível de cortesia. Numa outra perspectiva, a elevada orientação cortês mitiga os efeitos negativos de fracas cotações noutras dimensões, reforça os efeitos positivos de boas cotações noutras dimensões, e reforça igualmente os efeitos negativos de fracas orientações noutras categorias comportamentais.

c) Na mesma senda de Rego (2000), os dados aqui expostos sugerem que, relativamente aos estudantes, os professores valorizam mais fortemente a conscienciosidade - o inverso ocorrendo com o comportamento de apoio. De qualquer modo, é indubitável que ambos os tipos de inquiridos valorizam fortemente essas duas dimensões comunicacionais. Esta notória convergência retira crédito à tese segundo a qual os estudantes são portadores de uma visão naif da actividade docente, e se deixam "seduzir" por posturas corteses/simpáticas. O que este estudo reitera é, precisamente, que os estudantes não se deixam deslumbrar por posturas "apenas simpáticas". Tal como os professores, os estudantes consideram que a eficácia comunicacional docente implica ser consciencioso na preparação e organização das aulas, empenhar-se activamente em que os alunos apreendam os conhecimentos, ilustrar a exposição com exemplos práticos, ser cuidadoso no modo como as aulas são ministradas. d) Esta consistência sugere que podemos estar perante comportamentos docentes de elevado potencial para a melhoria da qualidade no ensino superior, designadamente no que concerne ao processo ensino-aprendizagem. Lançase aqui o repto para que futuros investigadores explorem novos caminhos de pesquisa, nomeadamente testando em que grau as categorias comportamentais aqui expostas explicam a motivação dos estudantes, a auto-confiança e o desempenho académico.

e) Uma última menção pode ser projectada sobre o papel exercido pelas áreas disciplinares. Em geral, não são detectáveis diferenças consideráveis entre as áreas humanísticas e de ciências. Ou seja: genericamente falando, os inquiridos valorizam as categorias comportamentais quaisquer que sejam as disciplinas a que se reportam. $\mathrm{O}$ único dado digno de explicitação é o que sugere que a facilitação da comunicação é mais ponderada na área de ciências que na de humanidades. Pode presumir-se que os alunos requerem que os professores destas matérias traduzam a complexidade e/ou cientificidade subjacente em linguagem simples, atractiva e assente em exemplos práticos que desvaneçam o véu de hermetismo. Futuras investigações poderão sondar mais minuciosamente esta temática - mediante o tratamento autónomo de maior número de áreas disciplinares (v.g., ciências, línguas, humanidades, matemática e computação, engenharias).

Em suma, a pesquisa comporta algumas limitações que importa ultrapassar, mas os seus méritos são incortornáveis. Primeiro: as boas propriedades psicométricas do instrumento traçam oportunidades de investigação que importa explorar. Segundo: estão lançadas algumas bases para a detecção de episódios comportamentais presumivelmente pertinentes para o incremente de melhorias no processo ensino-aprendizagem e, globalmente, na qualidade do ensino superior.

\section{Referências}

Alessandra, T. \& Hunsaker, P. (1993). Communicating at work. New York: Simon \& Shuster.

Bailey, D. \& Bennett, J.V. (1996). The realistic model of higher education. Quality Progress, November, 77-79.

Byrne, B.M. (1998). Structural equation modeling with lisrel, prelis, and simplis. London: Lawrence Erlbaum Associates.

Crainer, S. (1999). As melhores citações de gestão. Executive Digest.

Ellington, H. \& Ross, G. (1994). Evaluating teaching quality throughout a university. Quality Assurance in Education, 2(2), 4-9.

Feigenbaum, A.V. (1994). Quality education and America's competitiveness. Quality Progress, September, 83-84.

Hackman, J.R. \& Wageman, R. (1995). Total quality management: empirical, conceptual and practical issues. Administrative Science Quarterly, 40, 309-342.

Hansen, W.L. \& Jackson, M. (1996). Total quality improvement in the classroom. Quality in Higher Education, 2(3), 211-217.

Helms, S. \& Key, C.H. (1994). Are students more than costumers in the classroom? Quality Progress, September, 97-99. 


\section{Eficácia Comunicacional na Docência Universitária}

Heyman, R. (1996). Cuidado com os equívocos. Executive Digest, Agosto, 68-70.

Horine, J.E., Hailey, W.A. \& Rubach, L. (1993). Shaping America's future. Quality Progress, October, 41-60.

Horsburgh, M. (1999). Quality monitoring in higher education: the impact on student learning. Quality in Higher Education, 5(1), 9-25.

Joreskog, K. \& Sorbom, D. (1993). Lisrel 8: Structural Equation Modeling with the Simplis Command Language. Scientific Software International.

Kline, P. (1994). An Easy Guide to Factor Analysis. London: Routledge.

Marsh, H.W., Hau, K., Chung, C. \& Siu, T.L.P. (1998). Confirmatory factor analyses of chinese students' evaluations of university teaching. Structural Equation Modeling, 5(2), 143-164.

Montano, C.B. \& Utter, G.H. (1999). Total quality management in higher education. Quality Progress, August, 52-59.

Nunnally, J.C. (1978). Psychometric Theory ( $2^{\text {nd }}$ ed.). New York: McGraw-Hill.

O' Hair , M.J. \& Odell, S.J. (1995) (Orgs.), Educationg teachers for leadership and change - teacher education yearbook III (pp. 285-301). Thousand Oaks, California: Corwin Press.

Podsakoff, P. M., \& Organ, D. W. (1986). Self-reports in organizational research: problems and prospects. Journal of Management, 12, 531- 544

Race, P. (1994). Quality for some? What about the rest? Quality Assurance in Education, 2(2), 10-14.

Rego, A. (2000). Eficácia comunicacional dos docentes universitários - operacionalização de um constructo. Psicologia, Educação e Cultura, IV(1), 127-140.

Rego, A. \& Sousa, L. (2000). Impactos dos comportamentos de cidadania docente sobre os alunos universitários - a perspectiva dos estudantes e dos professores. Linhas Críticas, 6(10), 9-30.
Rowley, J. (1996). Measuring quality in higher education. Quality in Higher Education, 2(3), 237-255.

Ruyter, K., Wetzels, M. \& Bloemer, J. (1998). On the relationship between perceived service quality, service loyalty and switching costs. International Journal of Service Industry Journal, 9(5), 436-453.

Sallis, E. (1993). Total quality management in education. London: Kogan Page.

Schargel, F.P. (1994). Teaching TQM in a inner city high school. Quality Progress, September, 87-90.

Scharples, K.A., Slusher, M. \& Swain, M. (1996). How TQM can work in education. Quality Progress, May, 75-78.

Shemwell, D.J., Yavas, U. \& Bilgin, Z. (1998). Customer-service provider relationships: an empirical test of a model of service quality, satisfaction and relationship-oriented outcomes. International Journal of Service Industry Management, 9(2), 155168.

Sirvanci, M. (1996). Are students the true customers of higher education? Quality Progress, October, 99-102.

Stringer, M. \& Irwing, P. (1998). Students' evaluations of teaching effectiveness: a structural modelling approach. British Journal of Educational Psychology, 68, 409-426.

Weller, L. D. (1996). The next generation of school reform. Quality Progress, October, 65-70.

Yorke, M. (1997). This way QA? Quality Assurance in Education, 5(2), 97-100.

Zbaracki, M. J. (1998). The rhetoric and reality of total quality management. Administrative Science Quarterly, 43, 602-636.

Recebido em 14.02.2001

Aceito em 11.01.2002 


\section{A. Rego}

\section{Anexo}

\section{Escalas Usadas Para Medir os Impactos dos Docentes Sobre os Estudantes}

\begin{tabular}{|l|l|l|l|l|l|l|l|}
\hline Era um péssimo comunicador & 1 & 2 & 3 & 4 & 5 & 6 & 7 \\
\hline
\end{tabular}

\begin{tabular}{|l|l|l|l|l|l|l|l|}
\hline Todos os professores deveriam ser como ele & 7 & 6 & 5 & 4 & 3 & 2 & 1 \\
\hline
\end{tabular}

\begin{tabular}{|l|l|l|l|l|l|l|l|}
\hline Era um prazer ir às suas aulas & 7 & 6 & 5 & 4 & 3 & 2 & 1 \\
\hline
\end{tabular}

\begin{tabular}{|l|l|l|l|l|l|l|l|} 
Foi um dos professores mais fracos que conheci & 1 & 2 & 3 & 4 & 5 & 6 & 7 \\
\hline
\end{tabular}

\begin{tabular}{|l|l|l|l|l|l|l|l|}
\hline Ir ou não às suas aulas era irrelevante & 1 & 2 & 3 & 4 & 5 & 6 & 7 \\
\hline
\end{tabular}

\begin{tabular}{|l|l|l|l|l|l|l|l|}
\hline As suas aulas eram um excelente meio de se aprender & 7 & 6 & 5 & 4 & 3 & 2 & 1 \\
\hline
\end{tabular} 